\title{
A EDUCAÇÃO NA MODERNIDADE E A MODERNIZAÇÃ̃ DA ESCOLA NO BRASIL: SÉCULO XIX E INÍCIO DO SÉCULO XX
}

\author{
Syomara Assuite Trindade \\ Irani Rodrigues Menezes
}

\section{RESUMO:}

Este artigo tem como objetivo discutir algumas ideias educacionais que se desenvolveram na modernidade e como estas ideias, configuradas na renovação da concepção de educação e na implantação de novos métodos de ensino, se apresentaram na modernização da instrução pública no Brasil, no final do século XIX e início do século XX. Destacam-se os debates sobre a renovação pedagógica e os métodos de ensino; entre eles: a aplicação do sistema lancasteriano no país, o método intuitivo e a influência das ideias pedagógicas escolanovistas como instrumento de reconstrução da sociedade brasileira, mediante a reconstrução da educação. As novas concepções e os novos métodos de ensino transferem o foco de conhecimento centrado no professor, para as experiências da criança.

Palavras-chave: modernidade - métodos de ensino - renovação pedagógica.

\section{EDUCATION IN MODERN TIMES AND THE MODERNIZATION OF SCHOOL IN BRAZIL: $19^{\text {TH }}$ CENTURY AND BEGINNING OF $20^{\text {TH }}$ CENTURY}

\begin{abstract}
:
The objective of this article is to discuss some educational ideas developed in modern times and how these ideas, arranged on the renewal of the conception of education and on the introduction of new teaching methods, have been presented in the modernization of public schooling in Brazil, in the end of the $19^{\text {th }}$ Century and in the beginning of the $20^{\text {th }}$ Century. The debates concerning pedagogical renewal and the teaching methods are the main points; among them: the implementation of the Lancastrian system in the country, the intuitive method and the influence of the New School pedagogical ideas as a reconstruction tool of the Brazilian society, by the reconstruction of education. The new conceptions and the new teaching methods transfer the focus of knowledge from the teacher to the child's experiences.
\end{abstract}

Keywords: - modernity- teaching methods - pedagogical renewal.

O presente texto visa discutir algumas ideias educacionais que se desenvolveram na chamada modernidade e como elas se apresentaram na modernização da instrução pública no Brasil, no final do século XIX e início do século XX. Dentre essas ideias, manifestas na renovação da concepção de educação e na implantação de novos métodos de ensino, destacam-se o ensino mútuo/monitorial ou lancasteriano, o método intuitivo e as ideias pedagógicas escolanovistas. Para situar o tema, torna-se necessário trazer para a discussão alguns pensadores que se destacaram, ao longo dos séculos, partindo do século XVI.

Embora alguns historiadores situem o início do período moderno em 1457, com a queda do Império do Oriente, a noção de tempos modernos na perspectiva do corte 
cronológico é relativa. Cada início de século se constrói uma identidade com a definição de um campo de diferenciações, que introduz o moderno permeado pelo antigo.

Neste trabalho a noção de modernidade é tratada como a visão de tempos modernos que se vincula às visões de mundo que surgem entre os séculos XV e XVII, quando profundas mudanças/revoluções nos campos da religião e da ciência, no mundo do trabalho e nas formas de organização da sociedade, dão lugar a uma maneira de entender o mundo, natural e social, baseada em dicotomias (GINZBURG, 1989 apud ALVES, 2004, p. 25).

Os séculos XVI e XVII constituem os complexos processos da modernidade, em que velho e novo se confrontam, com todas as suas características: a secularização, o individualismo, o domínio da natureza, o Estado moderno, a nova ciência, a afirmação da burguesia e da economia de mercado e capitalista, a cultura laica. Velho e novo se encontram: a dimensão antropocêntrica do humanismo ao lado do sentido de liberdade e de inovação; o retorno da leitura dos clássicos antigos para a criação de uma nova estética; a atenção à natureza, ao macrocosmo, torna-se mais técnica, mais científica, sob o primado da observação e da dedução. "Também o indivíduo deve submeter-se a uma remodelação, através do ideal do 'cortesão' e das regras de 'sociabilidade', que estabelece os princípios e as formas da socialização”(CAMBI, 1999, p. 244).

Transformações radicais são operadas no século XVI, nos terrenos político, religioso, ético, social e técnico, que configuram a pedagogia e a educação (CAMBI, 1999, p. 244). No terreno político, o nascimento do Estado moderno, diga-se Estado absoluto, é determinante para a organização de uma educação na família, na escola, em associações, num processo de envolvimento e conformação do indivíduo. No terreno religioso o século XVI caracteriza-se como uma laceração entre Reforma e Contra-Reforma e como um século de fermentações teológicas e pastorais, que ativa um modelo de sociedade cristã, mais evangélica de um lado e mais disciplinar de outro. A ética se vincula à natureza e a sociedade e se relaciona às escolhas dos indivíduos, subjetividades e visões de mundo. Mudam-se as técnicas educativas e escolares para atender a uma sociedade disciplinar que tende a reprimir, controlar e inserir o indivíduo em sistemas de controle cada vez mais pertencentes à ideologia e à burocracia do governo, seja ele laico ou religioso-eclesiástico.

No século XVII, vão se afirmando os processos sociais de racionalização, de secularização, de domínio, e os mitos que guiarão seu crescimento e desenvolvimento: "os mitos do Estado, do poder e do dinheiro, o da Razão e do Progresso ou o mito da Revolução, o do Trabalho e o da Infância acompanhado do mito do 'Bom Selvagem'" (CAMBI, 1999, p. 278). Para o referido autor, esses mitos virão caracterizar a mentalidade em curso de laicização, como princípio normativo e valor-guia no indivíduo e em seus processos de formação.

Sobre as ideias educacionais dos tempos modernos, iniciamos pela renascença, período em que se elabora o ideal pedagógico vivido pela França, desde o século XVI até o fim do século XVIII, na formação do espírito clássico. A renascença marca, do ponto de vista pedagógico, uma ruptura com o passado da educação escolástica da Idade Média. Nesse período, aparece algo novo - as grandes doutrinas pedagógicas expressas no pensamento de Rabelais, segundo o qual "nada havia para guardar do antigo ideal pedagógico, 'a escolástica'. Era necessária uma revolução que destruísse o velho ensino e pusesse em seu lugar um sistema inteiramente novo" (DURKHEIM, 1995, p. 170). Assim, urge apagar todo vestígio da escolástica na mente dos homens, para que a razão pudesse ter acesso a ela.

Todos os grandes pensadores da época também assumiram tal atitude por considerarem a escolástica uma praga pública. Assim, no século XVI a tradição escolar deixa de se desenvolver na mesma direção do passado, para tomar um rumo inteiramente 
novo, o que significava não apenas enunciar o pensamento novo, mas elaborar a sua teoria, o que fez eclodir, pela primeira vez na história, segundo Durkheim (1995), uma literatura pedagógica na França representada por Rabelais, Montaigne, Vives, Erasmo, entre outros.

Duas revoluções no âmbito das ideias pedagógicas se destacaram nos séculos XVI e XVII. No século XVI, essas ideias se devem a dois grandes pensadores: Rabelais e Erasmo. O primeiro, Rabelais, afirma ser a natureza boa, inteira sem reserva, sem restrição, sem regulamento, sem disciplina. Para Rabelais, regulamentar a natureza "é impor-lhe limites, é limitá-la e, por conseguinte, mutilá-la” (DURKHEIM, 1995, p. 174).

O princípio da natureza boa, aplicado à educação, prima pela necessidade de desenvolver na criança todas as funções do corpo e da mente, sem distinção, no sentido de formar homens completos e universais e libertar a natureza humana de uma educação artificial e sem sentido. Contudo, para Durkheim (1995) a pedagogia de Rabelais é norteada por um sentido aristocrático, visto que ele quer fazer do seu aluno um sábio, um erudito, ou seja, o objetivo desta educação era formar inteligências enciclopédicas.

$\mathrm{O}$ segundo, Erasmo, reduz toda a cultura humana à mera cultura literária e toma quase com exclusividade o estudo da antiguidade clássica, Grécia e Roma. Com ele o formalismo da escolástica cede lugar a um novo gênero, o do formalismo literário. A arte de escrever e de falar ocupa o lugar que era o do saber na pedagogia de Rabelais. A pedagogia de Erasmo é também norteada por um sentido aristocrático, apegado ao dizer, cujo objetivo da educação era formar mentes polidas e capazes de cumprir um papel honrado na sociedade (DURKHEIM, 1995, p. 192).

No início do século XVII, deu-se a segunda revolução das ideias pedagógicas na Europa, com dois grandes teóricos: Ratichius e Comênius. Ratichius protesta contra o fato de as letras ocuparem um lugar primordial no ensino, e contra os anos que a criança perde para aprendê-las. Para Ratichius "o pensamento contido em todos os seus princípios era o de que tudo deveria ser feito na sua ordem natural" (MONROE, 1976, p. 216-217), ou seja, tudo deveria seguir o curso da própria natureza. Assim como a compreensão humana deve obedecer às leis da natureza, deve-se também obedecer ao método natural na arte de ensinar.

Muitos dos princípios de Ratichius foram considerados como verdades e tiveram influências reformadoras. Monroe (1976) traz alguns: repetir muitas vezes cada coisa; tudo deve ser ensinado primeiro na língua materna; nada se deve aprender de cor; primeiro a coisa e depois a sua explicação; tudo deve ser aprendido por meio da experiência e da investigação ou experimentação. Alguns dos princípios propostos por Ratichius anteciparam reformas metodológicas como a de Comênius e a de Pestalozzi criada no século XIX.

O princípio fundamental das ideias pedagógicas de Comênius diz respeito à necessidade de formar o homem para a vida espiritual, mas, também, para a vida temporal e civil (DURKHEIM, 1995). Para Comênius era preciso inverter os métodos que valorizavam os textos no lugar do conhecimento das coisas. As ideias de Comênius foram o ponto de partida de rompimento com os métodos da renascença e da escolástica, para colocar a criança na escola das coisas.

Assim, nasce o movimento em prol da pedagogia realista que desembocou na constituição das primeiras escolas secundárias da Europa, onde o ensino das realidades, das coisas e das ciências tomou o lugar do ensino puramente literário. A ideia geral do método aplicado por Comênius, a exemplo de Rabelais, é a natureza. Ele advoga três canais pelos quais o conhecimento chega até nós: "os sentidos, o intelecto e a revelação divina; 'diz' que o erro cessará quando se conservar entre eles o equilíbrio" (MONROE, 1976, p. 219). 
Manacorda (1989) afirma que a reelaboração de toda a enciclopédia do saber e sua adequação às capacidades infantis são o grande mote da pedagogia de Comênius, considerada, para este grande pedagogo, a necessária regeneração de toda a sociedade. Comênius valoriza a pesquisa e todas as metodologias chamadas, hoje de ativas. Suas ideias filiam-se diretamente à pedagogia do século XVIII e também às educacionais do final do século XIX e início do século XX no Brasil.

O modelo de formação intelectual e cultural elaborado pela sociedade moderna, nos séculos XVI e XVII, dá origem ao nascimento da escola moderna, racionalizada na estrutura e nos programas, e valorizada na sua função civil. O homem civil, bem educado, torna-se o modelo de conformação social da aristocracia. Depois, este modelo se estende para os grupos burgueses e, por fim, à sociedade, excetuando-se o povo.

O Século XVIII, segundo Cambi (1999), é o

divisor de águas entre mundo moderno e contemporâneo: decanta as estruturas profundas, realiza as instâncias-guia do primeiro, contém os 'incunábulos'do segundo. E a laicização aliada ao reformismo (político e cultural sobretudo) são as bases que sustentam este papel do século das luzes (CAMBI,1999, p. 324).

No âmbito político, afirmam-se novas classes, novos povos, novos modelos de Estado e de Governo. No âmbito cultural, o grupo de intelectuais que difunde "as luzes" inspira as políticas de reformas. Nesse contexto, a Europa é caracterizada pelo pluralismo, pelas tensões, pelos ideais de liberdade e de reforma que serão típicos dos séculos XIX e $\mathrm{XX}$.

No século XVIII, a educação é colocada no centro da vida social e tem a função de homologar classes e grupos sociais, recuperar todos os cidadãos para a produtividade social, construir em cada homem a consciência de cidadão e emancipá-lo intelectualmente, liberando-o de preconceitos, tradições acríticas, fés impostas e crenças irracionais (CAMBI, 1999, p. 326). A educação emancipa-se dos modelos religioso-autoritários do passado e reivindica para o homem a formação de si próprio em seu processo de autonomia e de liberdade.

É nesse século que se constrói o "mito da educação", sendo ela capaz de renovar a sociedade. Desse modo, a educação é o meio mais próprio e eficaz de dotar a sociedade de comportamentos homogêneos e funcionais para o seu próprio desenvolvimento.

Nesse contexto, a escola é renovada radicalmente nos níveis: da organização, delineando-se um "sistema escolar" orgânico e submetido a controle público; dos programas de ensino, acolhendo as novas ciências, as línguas nacionais e os saberes úteis; da didática dando lugar a processos de ensino mais científicos ou mais empíricos ou mais práticos. Especial atenção é dada à alfabetização e à difusão da cultura como processo de crescimento democrático coletivo, que se liga mais tarde à imprensa e à difusão do livro, também para os grupos populares.

É no século XVIII que se impõe o direito à instrução do povo, sobretudo na França, que o liberte das condições de atraso e marginalidade psicológica e cognitiva e o recoloque como elemento produtivo no âmbito da sociedade. A demanda por reformas educacionais porá em destaque o papel a ser exercido pelo "poder político" de organizador e controlador de um sistema escolar orgânico, "racionalizando-o num conjunto de ordens e graus, distintos e interligados ao mesmo tempo" (CAMBI, 1999, p. 331).

$\mathrm{Na}$ Inglaterra, no contexto da revolução industrial, na metade do século XVIII, se afirmam novos métodos de ensino promovidos por particulares, para atender às demandas de uma nova classe que vinha se desenvolvendo com o avanço da fábrica: a classe operária. Nesse contexto são propostos dois métodos de ensino: o mútuo e o intuitivo. 
Cabe assinalar que a fábrica apareceu antes das máquinas e produziu os primeiros sintomas de mal-estar social, cada vez mais agudos na sociedade do mundo europeu. O ideal de renovação da sociedade, via educação, consubstanciado na Europa, se afirma, no Brasil, no final do século XIX e início do século XX, com os métodos de ensino mútuo e intuitivo, como será visto mais adiante.

\section{O método de ensino mútuo ou sistema lancasteriano}

O ensino mútuo surge na Inglaterra entre os séculos XVIII e XIX. Manacorda (1989) cita alguns exemplos muito antigos desta experiência, contudo, segundo o autor, a sistematização didática e a difusão de um plano nacional de instrução popular foram iniciadas por um pastor anglicano chamado Andrew Bel, juntamente com o quaker Joseph Lancaster, que dirigiu uma escola em Madras, instituída pela Companhia das Índias Orientais, para os filhos de seus soldados europeus. Lancaster, em 1798, abriu uma escola para crianças pobres em Londres.

Bel também publicou um livro chamado An experiment in education (1797), em que sugere um sistema de instrução no qual uma escola ou uma família poderia instruir-se a si mesma, através da orientação de um mestre ou de um parente. A experiência foi aplicada no asilo masculino de Madras e um dos seus objetivos era economizar as despesas com instrução e acelerar os progressos dos alunos (MANACORDA, 1989, p. 257).

Mais tarde, Lancaster criou o método de ensino mútuo ou monitorial e publicou, em 1803, o livro denominado Improvements in education, que objetivava melhorias para a educação do povo. Enquanto Lancaster propunha uma educação religiosa não confessional, Bell propunha uma educação no espírito da Igreja oficial.

O método lancasteriano de ensino mútuo ultrapassou os muros da Inglaterra e se espalhou por todo o mundo de língua inglesa. Foi aplicado no ensino elementar masculino, estendeu-se para o ensino feminino, para a educação de adultos e para as escolas de nível superior. Segundo Manacorda (1989), não se tratava apenas de um método didático, mas em primeiro lugar, de uma opção política, tornando-se para a Inglaterra o substituto de um sistema nacional de escolas, daí a denominação de sistema lancasterino. Essa opção política foi implantada na rede de ensino da Inglaterra e nos países de língua inglesa. No Brasil também foi uma opção política e estava na Lei de 15 de novembro de 1827, a qual determinava que "[...] as escolas serão de ensino mútuo nas capitais das Províncias, e serão também nas cidades, vilas e lugares populosos delas, em que for possível estabelecer-se". (FARIA FILHO, 2000, p. 141)

José Hamel (1819, p. 5 apud MANACORDA, 1989, p. 258), na introdução do seu livro "Ensino Mútuo", traduzido para o italiano, se perguntava: "Convém ou não difundir a instrução no mundo? Devemos ou não desejar que as classes inferiores recebam pelo menos os princípios de uma instrução elementar?" O método de ensino mútuo era, portanto, a resposta a este medo dos conservadores, de que a instrução pudesse perturbar o Estado, desde quando este método poderia instruir até 1000 alunos com um só mestre, em vez de instruir apenas 50 alunos nas classes tradicionais, do ensino individual.

A generalização e a universalização deste modelo de ensino se deram de forma rápida e "situa a escola elementar no centro dos processos de transformação social e cultural que atingiram todo o Ocidente nos séculos XIX e XX" (SOUZA, 1998, p. 22). Também para Bastos (2005), a difusão do ensino mútuo pelo mundo está ligada à necessidade de estender a educação a todas as classes sociais e se fundamenta nos 
propósitos iluministas. Esta forma de ensino também chega ao Brasil, no momento posterior a sua independência em 1822 .

\section{O método do ensino mútuo no Brasil}

O século XIX foi rico nos debates sobre as ideias pedagógicas e sobre o problema da instrução no Brasil. Através de publicação de livros, matéria em jornais e publicação de textos legais, aparece o interesse das elites pela educação. Ressalta-se no período o ideário civilizatório iluminista que se irradiava, a partir da Europa, para boa parte do mundo e também para o Brasil. Assim, estava fincada a ideia da necessidade de alargar as possibilidades de acesso a um número cada vez maior de pessoas às instituições educacionais e às práticas civilizatórias.

Para Faria Filho (2000), as primeiras propagandas do método de ensino mútuo no Brasil datam de meados da segunda década do século XIX, cujas discussões tiveram lugar após a proclamação da independência em 1822. Moacyr (1936, p.71, apud BASTOS, 2005, p. 41) nos diz que, nesta época, as medidas oficiais denotam o interesse na implantação do método, em virtude da facilidade e precisão com que desenvolve o espírito da criança e a prepara para a aquisição de novas e mais transcendentes ideias.

O método de ensino mútuo já havia sido abandonado na Inglaterra, quando deputados brasileiros, que tinham ido à Europa com a missão específica de organizar a educação, ao voltarem, propuseram sua implantação entre nós. Esta escolha, segundo Freire (1989, p. 49), se deu em decorrência da falta de formação de docentes para o magistério primário.

Assim, a partir de 1820, todo o debate pedagógico no Brasil centrou-se em torno do método de ensino mútuo, que foi implantado, de forma oficial, por uma ordem ministerial, a qual exigia que cada província do Império enviasse um soldado, a fim de aprender o método para propagá-lo na província de origem e aplicá-lo nas escolas de primeiras letras. Desse modo, os professores eram recrutados nos quadros militares, mantendo-se assim até o Decreto de 01/03/1837 do Império, que instituiu a incompatibilidade entre as funções de militar e de professor público (MOACYR, 1936, p.71 apud BASTOS, 2005, p.41).

Mas, foi a Lei de 15 de novembro 1827, já referida anteriormente, que propôs a criação de escolas primárias com a adoção do método de ensino mútuo. As discussões sobre o método centravam-se, principalmente, sobre a necessidade de espaços, de materiais e de formação de professores. Essas discussões vão "se processando no Brasil no decorrer dos anos 1840 e meados dos anos 1870 do século XIX" (FARIA FILHO, 2000, p. 142).

Embora as vantagens do método em questão sejam destacadas por alguns representantes da Assembleia Constituinte de 1823, a exemplo do Sr. Machado Francisco Ribeiro de Andrade Machado (BASTOS, 2005, p. 41), muitos outros discutem os obstáculos com relação a implantação do método de ensino mútuo. Entre eles se destacam: a falta de prédios escolares adequados e de material necessário; a ausência de instituições que pudessem formar professores para tal fim; o descontentamento dos mestres pela falta de proteção dos poderes públicos e pela falta de recompensa salarial.

Freire (1989, p. 53 - 55) refere-se a vários relatórios, sobre as escolas de primeiras letras e método lancasteriano, que denunciam a sua aplicação no Brasil, por exemplo:

O Relatório de 1833 denunciava que o método de ensino público, o lancasteriano, não apresentava bons resultados. Assim o governo não deveria criar mais escolas enquanto esse método não fosse aperfeiçoado. Como não havia prédios públicos para escolas, tinha-se que construí-los ou alugá-los. 
O Relatório de 1835 continua apontando a ineficiência do ensino mútuo com relação à ausência de livros e materiais escolares adequados para o desenvolvimento das atividades, assim como a ausência de prédios escolares de acordo com as exigências do método.

O Deputado Torres Homem, em 1847, profere um discurso na Câmara em defesa do projeto de reforma da instrução pública, no qual denuncia que uma das causas da péssima situação do ensino residiria no método mútuo, também chamado monitorial, além do descaso das autoridades governamentais para com a educação pública (FREIRE, 1989).

Diante das críticas constatadas nestes e em outros relatórios, citados por Freire (1989) e por Bastos (2005), parece-nos crer que o método de ensino mútuo não era adequado para o Brasil. Mesmo assim, documentos analisados por Bastos (2005) comprovam a sua permanência durante o período monárquico como solução para a falta de professores.

Por outro lado, assim como no Brasil, na Europa e na América, críticas acirradas foram feitas ao método lancasteriano, pelo fato de não haver estrutura física e professores preparados para desenvolverem as atividades do método. As críticas centravam-se na incompetência dos monitores, no sistema empírico e prático, baseado em procedimentos mecânicos, desprovidos de valor educativo; na inculcação de fórmulas e receitas; na transmissão de conhecimentos superficiais que não levavam os alunos à reflexão e não desenvolvia a inteligência.

Dessa forma, o aluno tornou-se a grande vítima da mecânica do ensino mútuo, o qual foi considerado preso a um verdadeiro sistema militar, que o levava a agir somente mediante uma ordem e a submeter-se a um condicionamento destinado a torná-lo um cidadão dócil e obediente (BASTOS, 2005).

A partir de 1870, segundo Faria Filho (2000), a vertente da discussão sobre os métodos na forma de organizar a classe sofre uma definitiva inflexão no meio educacional brasileiro, sobretudo a partir da divulgação e apropriação das ideias e experiências do educador Jean-Henri Pestalozzi. O curso da discussão muda para as relações pedagógicas do processo de ensino e aprendizagem do aluno. Os debates então se articularão em torno do chamado método intuitivo.

\section{O Método de Ensino Intuitivo}

O método de ensino intuitivo surgiu na Alemanha no final do século XVIII e foi adotado na segunda metade do século XIX nas escolas europeias, americanas e brasileiras, sendo Pestalozzi e Frobel os autores que influenciaram o referido método nos livros didáticos e nos compêndios de Pedagogia. Para Valdemarim (1998) deve-se ao Empirismo, através do conhecimento teorizado por Francis Bacon e John Locke, no século XVII, a influência destes procedimentos de ensino. Esses autores visualizaram uma nova forma de apropriação do mundo através dos sentidos como ponto de origem do conhecimento.

O método intuitivo, também chamado lições de coisas, "consistia na valorização da intuição como fundamento de todo o conhecimento, isto é, na compreensão de que a aquisição do conhecimento decorria dos sentidos e da observação" (SOUZA, 1998, p. 26), considerados primordiais na aprendizagem humana.

O novo método pode ser sintetizado em dois termos: observar e trabalhar; 


\begin{abstract}
Observar significa progredir da percepção para a idéia, do concreto para o abstrato, dos sentidos para a inteligência, dos dados para o julgamento. Trabalhar significa em fazer do ensino e da educação na infância uma oportunidade para a realização de atividades concretas similares aquelas da vida adulta (VALDEMARIM, 1998, p. 69).
\end{abstract}

Dessa forma o método intuitivo direcionou o desenvolvimento da criança do ponto de vista mental, moral e físico, e se generalizou como o mais adequado à instrução das classes populares, capaz de reverter a precariedade do ensino, no que se refere à leitura e à escrita, ao cálculo, à priorização da memória no processo de aprendizagem, à valorização da repetição em detrimento da compreensão entre outros pontos destacados por Valdemarim (1998).

O novo método, ancorado nas "lições de coisas", é divulgado em Exposições Universais, em alguns países da Europa, visando difundir a aplicação das práticas pedagógicas renovadas.

\title{
O método de ensino intuitivo no Brasil
}

Nos comentários de Faria Filho (2000), as discussões sobre a possibilidade do trabalho com o método intuitivo na escola primária brasileira permaneceram até a década de 1930 do século XX. Intelectuais, homens públicos, diretores e professores de escolas públicas e particulares tomaram para si a tarefa de remodelar a educação no Brasil; acreditavam no poder da educação para modificar o cenário da nação.

Uma das formas de divulgação do método se consubstanciou nas exposições escolares. O Brasil realizou sua primeira Exposição Pedagógica, em 1883, no Rio de Janeiro, no âmbito das Exposições Universais, que se constituíram um dos principais veículos de difusão das ideias e das práticas da nova tendência norteadora do ensino, principalmente o primário.

Schelbauer (2005) cita alguns dos responsáveis pela divulgação e aplicação do método intuitivo no Brasil: Benjamim Constant trouxe algumas ideias da educação dos sentidos para a reforma da instrução primária, decretada em 1871; Alambary Luz, como diretor da Escola Normal da Província do Rio de Janeiro (1868 - 1876) modernizou o ensino neste estabelecimento, com a aplicação do método intuitivo; Menezes Vieira, pioneiro na criação dos jardins-de-infância em 1875, ancorou-se nos trabalhos de Pestalozzi e Froebel; Leôncio de Carvalho preconizou na legislação educacional brasileira a "lição de coisas", mediante o decreto de 19/04/1879.

O Manual Primeiras Lições de Coisas de ensino elementar, para uso dos pais e professores, de Norman Allison Calkins, foi adaptado às condições do nosso idioma pelo Conselheiro Ruy Barbosa, em 1886, através da Imprensa Nacional no Rio de Janeiro. Esse texto foi republicado em 1950 pelo Ministério da Educação e Saúde, no volume 13 das Obras Completas de Rui Barbosa. Segundo Lourenço Filho (1978), a renovação educacional se fez refletir no domínio da didática em alguns colégios particulares mantidos por educadores norte americanos. Em 1882 Rui Barbosa refere-se aos novos procedimentos experimentados no Colégio Progresso no Rio de Janeiro. Outras experiências desenvolveram-se em São Paulo, na Escola Americana e no Colégio Piracicabano.

Até a década de 1930, os discursos político e da educação, produzidos no Brasil têm uma estreita relação entre estas inovações pedagógicas e o ideário liberal republicano de 
transformação social pela via da educação, quando as ideias da Escola Nova já se faziam presentes no cenário educacional brasileiro.

\section{A Escola Nova}

As experiências educacionais da Escola Nova, também chamada de Escola Ativa, surgiram no fim do século XIX e início do século XX na Europa, mais precisamente na França e nos Estados Unidos da América do Norte.

Esse movimento teve em John Dewey seu maior expoente nos Estados Unidos, cujas ideias educacionais são experimentadas num contexto de mudanças que se processavam na vida moderna. Essas mudanças aconteceram em decorrência do processo de industrialização e democratização da sociedade, o que exigia uma nova atitude diante da vida e da educação, no sentido de preparar a futura geração a pensar por si mesma.

Segundo Kilpatrick (1965, p. 20), essas mudanças "nasciam sob a influência do pensamento baseado na experimentação, ou, de modo geral, no desenvolvimento da ciência e de suas aplicações à atividade humana". Para o autor, essa nova forma de pensar distinguia o mundo moderno de qualquer período histórico precedente, e o mundo moderno apelava à educação para satisfazer suas exigências.

John Dewey (1973, p. 16) pensava a educação como "um processo de reconstrução e reorganização da experiência, pelo qual lhe percebemos mais agudamente o sentido, e com isso nos habilitamos a melhor dirigir o curso das nossas experiências futuras". As ideias de Dewey embasaram o surgimento de vários métodos, criados e aperfeiçoados por diferentes educadores, tais como: Kilpatrick com o Método de Projetos; Decroly com os Centros de Interesse, entre outros métodos que foram aplicados no Brasil na segunda metade da década de 1920.

De outro modo, teóricos da educação que lideravam o movimento da Escola Nova em vários países do mundo, entre o final do século XIX e ao longo do século XX, como Claparède, Montessori, Ferrière, também influenciaram os educadores brasileiros, através de suas obras ou de revistas especializadas. O sistema proposto por Maria Montessori, que ainda se mantém em muitas escolas brasileiras, exerceu influência marcante no Brasil, principalmente na rede privada do ensino - na educação infantil e no ensino primário.

Influenciados, especialmente, no pensamento escolanovista de John Dewey, os educadores brasileiros, Anísio Teixeira, Fernando de Azevedo, Sampaio Dórea, Lourenço Filho, Paschoal Lemme e Francisco Campos foram os mais importantes e ferrenhos representantes das ideias da Escola Nova e da luta por reformar a sociedade brasileira pela renovação e democratização da escola pública no Brasil, nas décadas de 1920 e 1930.

Os intelectuais da educação nova realizaram várias atividades de divulgação dessas ideias, entre elas a Conferência Nacional de Educação, realizada em 1931, na qual o então presidente da República, Getúlio Vargas, na instalação da mesa de conferência, convocou os educadores para definir o "sentido pedagógico da revolução de 1930". Assim, em 1932, os pioneiros lançaram e publicaram o chamado Manifesto da Educação Nova que se traduziu em uma política nacional de educação, como afirma Lemme (1984).

Em linhas gerais, o documento do manifesto refletia a concepção de educação "como um direito de todos, de acordo com as necessidades, aptidões e aspirações, dentro do princípio democrático da igualdade de oportunidades para todos" (LEMME, 1984, p. 264). Compreendia também uma nova concepção de infância à luz da psicologia, uma nova didática e uma nova metodologia, em que o aluno observador era substituído pelo 
experimentador, centro do processo educativo. O movimento escolanovista, como afirma Vidal, (2000, p. 515) "promoveu, nos anos 20, rupturas nos saberes e fazeres escolares". Não constituiu um "novo modelo escolar", mas produziu novas "formas" e "alterou a cultura escolar".

As reformulações do ensino no Brasil, com base no ideário escolanovista, iniciaramse na segunda metade da década de 1920 e atingiram vários Estados: Bahia, Ceará, Rio de Janeiro, São Paulo e Minas Gerais.

\section{Algumas considerações conclusivas}

As ideias educacionais da chamada "modernidade" iniciadas entre o século XVI e XVII se realizam no século XVIII na Europa e influenciam os discursos de educadores brasileiros na modernização da instrução pública no Brasil, no final do século XIX e início do século XX. Essas ideias são configuradas na renovação da concepção de educação e na implantação de novos métodos de ensino.

A generalização e universalização de uma escola elementar para todas as classes sociais situa a escola no centro dos processos de transformação social e cultural que atingiram todo o Ocidente nos séculos XIX e XX, o que justifica a difusão do ensino mútuo pelo mundo. Esta forma de ensino também chega ao Brasil no momento posterior a sua independência em 1822.

O movimento de modernização da educação brasileira iniciou-se no final do século XIX, mais precisamente com o advento da República, e estendeu-se às primeiras décadas do século $\mathrm{XX}$, quando o país passava por inúmeras transformações do ponto de vista político, social e econômico.

Essas transformações repercutiram intensamente na educação brasileira, gerando discussões e debates em torno da precariedade do ensino, da organização escolar, do atraso nos métodos e dos processos de ensino, com vistas a promover iniciativas de reformas na educação.

As reformas educacionais, além de serem provocadas pelas transformações políticas, sociais e econômicas que estavam ocorrendo no país, também eram impulsionadas pelas ideias pedagógicas que chegavam da Europa, em favor da renovação de métodos e processos de ensino.

Até a década de 1930, os discursos político e o da educação produzidos no Brasil têm uma estreita relação dessas inovações pedagógicas com o ideário liberal republicano de transformação social pela via da educação.

Embora se constate no Brasil as ideias de inovações pedagógicas, não houve a implantação do método do ensino mútuo/monitorial conforme proposto na Inglaterra. $\mathrm{O}$ que ocorreu na prática foi a proposição da criação de escolas primárias com a adoção do método, e muita discussão política em torno de suas vantagens e desvantagens, bem como sobre a sua implantação. Não existiam espaços adequados para comportar um maior número de alunos, nem materiais didáticos e nem professores formados para aplicação do método.

Com relação ao ensino intuitivo, a renovação educacional se fez presente nas escolas privadas, principalmente no Estado de São Paulo.

As discussões sobre a forma de se trabalhar com o método intuitivo na escola primária brasileira perduraram até a década de 1930 do século XX, quando as ideias da Escola Nova já se faziam presentes no cenário educacional brasileiro. 
A educação nova, proposta nas primeiras décadas do século XX, foi encarada como um instrumento de reconstrução da sociedade brasileira mediante a reconstrução da educação, cuja ideia guarda similaridade com as ideias de reconstrução da sociedade, via educação, iniciadas na modernidade no continente europeu.

\section{Referências}

ALVES, Nilda (Org.). Criar currículo no cotidiano. 2.ed. São Paulo: Cortez, 2004.

BASTOS, Maria Helena Câmara. O ensino monitorial/mútuo no Brasil (1827-1854). In: STEPHANOU, Maria; BASTOS, Maria Helena Câmara (Orgs.). Histórias e memórias da educação no Brasil. Petrópolis: Vozes, 2005, v. 2.

CAMBI, Franco. História da Pedagogia. São Paulo: Fundação Editora da UNESP (FEU), 1999. (Encyclopaidéia).

DEWEY, Jonh. Escola e democracia. São Paulo: Vozes, 1973.

DURKHEIM, Emile. A evolução pedagógica. Porto Alegre: Artes Médicas, 1995.

FARIA FILHO, Luciano Mendes de. Instrução elementar no século XIX. In: LOPES, Eliane Marta Teixeira; FARIA FILHO, Luciano Mendes de; VEIGA, Cynthia Greive (Orgs.). 500 anos de educação no Brasil. Belo Horizonte: Autêntica, 2000.

FREIRE, Ana Maria. Analfabetismo no Brasil. São Paulo: Cortez, 1989.

KILPATRICK, William Heardh. Educação para uma civilização em mudança. São Paulo: Melhoramentos, 1965.

LEMME, Paschoal. O manifesto dos pioneiros da educação nova e suas repercussões na realidade educacional brasileira. Revista Brasileira de Estudos Pedagógicos. Brasília, v. 65, n.150, p. 225-272, maio/ago. 1984.

LOURENÇO FILHO, Manuel Bergström. Introdução ao estudo da escola nova. São Paulo: Melhoramentos, 1978.

MANACORDA, Mário Alighiero. História da Educação. São Paulo: Cortez, 1989.

MONROE, Paul. História da educação. 11. ed. São Paulo: Editora Nacional, 1976.

SCHELBAUER, Analete Regina. O método intuitivo e lições de coisas no Brasil do século XIX. In: STEPHANOU, Maria; BASTOS, Maria Helena Câmara (Orgs.). Histórias e memórias da educação no Brasil. Petrópolis: Vozes, 2005. v.2

SOUZA, Rosa Fátima de. Espaço da educação e da civilização: origens dos grupos escolares no Brasil. In: SOUZA, Rosa Fátima de; VALDEMARIN, Vera Teresa; ALMEIDA, Jane Soares de. O legado educacional do século XIX. Araraquara: UNESP: Faculdade de Ciências e Letras, 1998. 
VALDEMARIN, Vera Teresa. Método intuitivo: os sentidos como janelas e portas que se abrem para um mundo interpretado. In: SOUZA, Rosa Fátima de; VALDEMARIN, Vera Teresa; ALMEIDA, Jane Soares de. O legado educacional do século XIX. Araraquara: UNESP: Faculdade de Ciências e Letras, 1998.

VIDAL, Diana Gonçalves. Escola nova e processo educativo. In: LOPES, Eliane Marta Teixeira; FARIA FILHO, Luciano Mendes de; VEIGA, Cynthia Greive (Orgs.). 500 anos de educação no Brasil. Belo Horizonte: Autêntica, 2000.

Artigo recebido em: 09/02/10

Aprovado para publicação em: 16/04/10 